\section{NON-STATE ACTORS IN THE INTERNATIONAL CLIMATE CHANGE REGULATORY FRAMEWORK}

Sina Bergmann ${ }^{1}$

DOI: https://doi.org/10.33344/vol14iss1pp88-100

Helsinki Law Review, 1/2020, pp. 88-104

(c) 2020 Pykälä ry, Mannerheimintie 3 B, 5th floor, 00100 Helsinki, Finland, and the author.

\section{Keywords:}

Climate change, Non-state actors, Global climate governance, United Nation Framework Convention on Climate Change, the Paris Agreement, Orchestration, Mitigation, Conference of the Parties

\section{ABSTRACT}

Global climate governance is multilateral and involves both state and non-state actors. This study sets to identify the ways in which non-state actors can access and participate in the international climate change regime under the UNFCCC and the 2015 Paris Agreement and to evaluate how they can influence law-making processes and outcomes under the agreements. The study further provides recommendations on how the involvement of non-state actors can be improved under the agreements. The study emphasizes that under the UNFCCC, non-state actors have an important role in acting as intermediaries under the orchestration governance model and in participating to the Conference of Parties and under the Paris Agreement, by exerting influence on state's nationally determined contributions. The study suggests that the role of non-state actors in formulating nationally determined contributions and in participating to the Conference of Parties should be further formalised and that the NAZCA portal should be improved.

1 LL.M., University of Helsinki. This article is based on a research essay written for a course on Environmental Law.

\section{INTRODUCTION}

The former United Nations Secretary-General Ban Ki-moon has characterised climate change as the "defining issue of our age". ${ }^{2}$ Climate change is not only a matter of concern for nation states but also other actors in the political, economic and societal sphere. World politics has moved away from a state-centric system towards a transnational one, in which nation states are not anymore the only players in the field. ${ }^{\mathbf{3}}$ In nearly every sector of world politics, actors other than nation states are playing a larger role in international governance. ${ }^{4}$ This is ever more so in the realm of climate change policy as it is a sector that affects nearly every aspect of economy. ${ }^{\mathbf{5}}$ In fact, the international arena of climate policy making has been described as being one of 'hybrid multilateralism' - a mix and mingle of state and non-state actors (hereinafter 'NSAs'). ${ }^{6}$ The role of NSAs in combatting climate change is an important one, since they have the potential of exerting considerable influence on decision makers, help build political support for climate action, and through their own actions, contribute to climate governance by developing new policies and business models. ${ }^{7}$ There is no universal definition of NSAs but are often considered to consist of business entities, nongovernmental organisations, activist groups, intergovernmental organisations, city networks, oil companies, trade unions, civil society and many more. ${ }^{\mathbf{8}}$

The aim of this study is threefold. Firstly, the article attempts to identify the ways in which NSAs can access and participate in the international climate change regime under the 1992 United Nations Framework Convention for Climate Change (hereinafter the 'UNFCCC') and the 2015 Paris Agreement (hereinafter referred as 'Agreement' and together as the 'Agreements'). Secondly, the paper aims to evaluate the extent to which these opportunities to access and participate in the Agreements enable NSAs to influence law-making processes and outcomes. Thirdly, this study will provide recommendations on how to improve the involvement of NSAs under the Agreements. While these three objectives are broad, the goal of the study is not to

2 UN Secretary-General: Opening remarks at 2014 Climate Summit [online]. Available from: https://www. un.org/sg/en/content/sg/speeches/2014-09-23/opening-remarks-2014-climate-summit [accessed 26 June 2020]

3 M. Ataman, 'The Impact of Non-State Actors on World Politics: A Challenge to Nation-States', 2 Turkish Journal on International Relations 1, 2003, p. 42.; T. Hale, 'The Role of Sub-state and Non-state Actors in International Climate Processes', Catham House: Energy, Environment and Resources Department, 2018 , p. 2.

4 Hale, 2018, p. 2.; J. Kuyper et al., 'Non-state Actors in hybrid global climate governance: justice, legitimacy and effectiveness in a post-Paris area', WIREs Climate Change 9, 2018, p. 1.

5 Hale, 2018, p. 2.; C. Streck, 'Innovativeness and Paralysis in International Climate Policy', 1 Transnational Environmental Law 1, 2012, p. 138.

6 Kuyper et al., 2018, p.1

7 Hale, 2018, p. 1 .

8 K. Bäckstrand et al., 'The democratic legitimacy of orchestration: the UNFCCC, non-state actors, and transnational climate governance', 26 Environmental Politics 4, 2017, p. 564.; F. Yamin, 'NGOs and International Environmental Law: A Critical Evaluation of their Roles and Responsibilities'. 10 Review of European Community \& International Environmental Law 2, 2001, p. 149 
address them exhaustively but to provide an introduction of them to the reader. The underlying purpose of addressing these objectives is to address the ongoing discussion around this important and current topic and participate in it.

Chapter 2 will introduce three different ways how NSAs can access and participate to the Agreements. Under the UNFCCC, NSAs can access and participate through orchestration and negotiation processes and under the Paris Agreement, through the mitigation process. Chapter 2 will also, in each subsection, analyse how NSAs influence law-making processes and outcomes through these different avenues of participation.

Chapter 3 will then put forth three distinct recommendations on how the access and participation of NSAs to the Agreements can be improved. These are: strengthening the role of NSAs in the Nationally Determined Contributions (hereinafter 'NDCs') formation process, improving NSA participation in the UNFCCC negotiations and developing the Non-state Actor Zone for Climate Action (hereinafter 'NAZCA') portal to further catalyse non-state action. The study will then conclude that, even though NSAs are increasingly taking a larger role in the climate change regulatory framework, efforts should still be made to improve their position.

\section{ACCESS, PARTICIPATION AND INFLUENCE}

This chapter is divided into three subsections, each introducing a way in which NSAs can access and participate in the Agreements. However, before addressing these a brief description of both the UNFCCC and the 2015 Paris Agreement is necessary as this will set the scene for the rest of the study. Both will be addressed separately under their respective section.

In the UNFCCC, important avenues for access and participation are through orchestration and the Conference of Parties (hereinafter 'COPs') and their side events. In the Paris Agreement, it is through mitigation. The three points raised here do not represent the only methods how NSAs can access and participate under the Agreements but, in the view of the author of this study, represents three important participation avenues. Moreover, these methods of access and participation are such that can be enhanced to achieve even better results. Each subsection will further evaluate to which extent these ways of access and participation influence law-making processes and outcomes.

\section{I United Nations Framework Convention on Climate Change - Orchestration}

The UNFCCC is an international treaty that emerged from the auspices of the Rio Conference. ${ }^{9}$ The Conference in Rio was, at the time in 1992, the biggest gathering of world leaders for the protection of the environment. ${ }^{10}$ Rio provided political momentum for climate change policy and was a starting point for non-state action and social networks in the climate change regime. ${ }^{11}$ The process leading to the adoption of the UNFCCC was a long one with both political and scientific input, accelerating its pace in the 1980s with the discovery of the growing ozone hole. ${ }^{12}$ Article 2 of the Treaty sets out its main objective being as the stabilisation of greenhouse gas concentrations in the atmosphere at a level that would prevent dangerous anthropogenic interference with the climate system. The treaty itself does not set any mandatory limits on greenhouse gas emissions for individual countries and does not contain any enforcement mechanism. ${ }^{13}$ Every year a COP is held, which is a supreme decision making body of the Convention in which all participatory states are represented. It reviews the implementation of the Convention and examines the commitments of the parties. ${ }^{14}$

\section{I.I Access and Participation}

Under the Convention, NSAs do not have a formal role. The treaty describes them as observers. ${ }^{15}$ In order to be seen as one, an NSA must be admitted by the COP as an observer to the UNFCCC process, after which they can send representatives to attend any session or meeting of the UNFCCC. ${ }^{16}$ Despite lacking a formal role, orchestration provides a way for NSAs to participate in the UNFCCC allowing them to affect outcomes on climate change policy, such as carbon neutrality. ${ }^{17}$ Orchestration is a governance mode in which international organisations and states mobilise intermediaries to pursue targets for collective goals. ${ }^{18}$ These intermediaries might be able to pressure states or other actors to achieve certain goals and then monitor and evaluate

9 R. Lyster et al., Environmental \& Planning Law in New South Wales (The Federation Press, 2016), p. 236. 10 Encyclopedia Britannica: United Nations Conference on Environment and Development [online] Available from: https://www.britannica.com/event/United-Nations-Conference-on-Environment-andDevelopment [Accessed 26 June 2020].

11 Bäckstrand et al., 2017, p. 561.

12 D. Freestone, 'The International Climate Change Legal and Institutional Framework: An Overview', UNSW Law Research Paper No. 2009-38, 2009, p. 2

13 United Nations: Conference of the Parties [online]. Available from: https://unfccc.int/process/bodies/ supreme-bodies/conference-of-the-parties-cop [Accessed 26 June 2020].

14 ibid.

15 Article 7.6 of the United Nations Framework Convention on Climate Change 1992

16 United Nations: How to obtain observer status [online]. Available from: https://unfccc.int/process-andmeetings/parties-non-party-stakeholders/non-party-stakeholders/how-to-obtain-observer-status [Accessed 26 June 2020]

17 K. Bäckstrand \& J. Kuyper, 'The democratic legitimacy of orchestration: the UNFCCC, non-state actors, and transnational climate governance', Environmental Politics 4, 2017, p. 770

18 ibid., p. 767 . 
to what extent those goals have been met. ${ }^{19}$ In an usual context, an orchestrator would be an international organisation, the intermediaries NSAs, and the targets states but these lines can become blurred. ${ }^{\mathbf{2 0}}$ Orchestration sets a soft and indirect mode of governance as opposed to a more hierarchical hard and direct mode. ${ }^{21}$ Two global climate governance orchestration

initiatives are the Lima-Paris Action Agenda (hereinafter 'LPAA') and NAZCA. These were both launched at COP2O in Lima and were intended to boost up non-state climate action. ${ }^{22}$ NAZCA and LPAA can both be conceptualised as 'meta-intermediaries', acting as instruments increasing intermediary availability. ${ }^{23}$ NAZCA is essentially a platform that acts as an online portal and aggregator of climate actions from substate and non-state actors. ${ }^{24}$ The LPAA is the 'fourth pillar ${ }^{\mathbf{2 5}}$ of the Paris Agreement and displays initiatives, enhances ambition and tracks and reports the actions of NSAs. ${ }^{26} \mathrm{It}$ is an initiative led by the governments of France and Peru, the Secretary-General of the United Nations and the Secretariat of the UNFCCC, bringing parties together to make commitments to fight climate change in various different topics. ${ }^{27}$

\subsubsection{Influence}

Within the UNFCCC framework, orchestration is an important way for NSAs to influence the outcomes of the UNFCCC climate change policy. Through orchestration, NSAs can act as contributors and governing partners. ${ }^{28}$ Orchestration not only influences national governments to aspire towards more ambitious climate action, ${ }^{29}$ but can catalyse non-state initiatives that facilitate the lead up to a carbon neutral future. ${ }^{30}$ Currently, the NAZCA portal has several initiatives by cities, companies, investors and civil society investors. ${ }^{\mathbf{3 1}}$ As an example of current initiatives, the Airport Carbon Accreditation can be mentioned. This initiative has been developed

19 J. Dryzek, 'The meanings of life for non-state actors in climate politics', 26 Environmental Politics 4, 2017, p. 790

20 ibid., p. 791

21 L. Hermwille, 'Making initiatives resonate: how can non-state initiatives advance national contributions under the UNFCCC?', 18 International Environmental Agreements: Politics, Law and Economics, 2018 p. 449 .

22 Bäckstrand \& Kuyper, 2017, p. 773-774

23 ibid., p. 772,775 .

24 ibid.; H. Van Asselt, 'The Role of Non-state Actors in Reviewing Ambition, Implementation, and Compliance under the Paris Agreement. Climate Law 6, 2016, p. 98.; Hermwille, 2018, p. 457.

25 The other three pillars are national pledges, the financing package and the negotiated agreement. See: Kuyper et al., 2018, p. 7.

26 Bäckstrand \& Kuyper, 2017, p. 773.

27 The Ministry of the Environment, Energy and the Sea of the French Government, 'The Lima-Paris Action Agenda: 10000 partners united for the climate: COP 21/CMP 11' [report], 2015, p. 4.

28 Kuyper et al., 2018, p. 2.

29 Hermwille, 2018, p. 447:; Dryzek, 2017, p. 795

30 Bäckstrand \& Kuyper, 2017, p. 774.

31 See: www.climateaction.unfocc.int by the Airport Council International Europe, and its objective is to reduce carbon emissions and achieve best practices in carbon management from operations within the control of the airport with an aim of becoming carbon neutral. ${ }^{\mathbf{3 2}}$ Similar initiatives that aim to lower carbon emissions are plenty on the NAZCA portal. Furthermore, NAZCA also played a role in the momentum that led to the adoption of the Paris Agreement. ${ }^{33}$

\subsection{United Nations Framework Convention on Climate Change - Conference of Parties}

\subsection{Access and Participation}

One practical yet important avenue for NSA participation is COPs and their side events. By participating as observers in these negotiations, forming part of constituencies and side events, NSAs can influence parties and take part in the development of international environmental law. ${ }^{\mathbf{3 4}}$ The side events provide a forum of interaction among national delegates, the media, and intergovernmental and observer organisation representatives. ${ }^{35}$ Around $60-75 \%$ of side events have related directly to matters that have been on the negotiation table. ${ }^{36}$ Side events facilitate informal exchange between stakeholders and provide input to negotiations. ${ }^{37}$

\subsubsection{Influence}

Ultimately, participation in COPs and their side events allow NSAs to exert their influence on decision makers. Participation to the negotiations allows NSAs to participate to agenda setting, policy formulation and decision making. ${ }^{38} \mathrm{NSAs}$ can gain influence over policymakers via membership in state delegations in exchange for their resources allowing them to shape policy outputs according to their own preferences. ${ }^{39} \mathrm{NSA}$ are also likely to find quick and effective solutions to diverse climate change issues. This is due to their expertise and built up knowledge of scientific, technical, social and economic nature. ${ }^{\mathbf{4 0}}$ In fact, NSAs might sometimes be better positioned than governments to provide expertise in certain sectors. ${ }^{41} \mathrm{NSAs}$ have less complex structures than governments and often possess expertise in various disciplines related to

32 Global Climate Action: Airport Carbon Accreditation [online]. Available from: http://climateaction.unfccc int/views/cooperative-initiative-details.html?id=7 [Accessed 26 June 2020].

33 Global Climate Action: About NAZCA [online]. Available from: http://climateaction.unfccc.int/views/ about.html [Accessed 26 June 2020]

34 Van Asselt, 2016, p. 95-96

35 Kuyper et al., 2018, p. 4 .

$36 \mathrm{H}$. Schroeder \& H. Lovell, 'The role of non-state actors and side events in the international climate negotiations', 12 Climate Policy 1, 2012, p. 23 37 ibid.

38 Kuyper et al., 2018, p. 4

39 T. Böhmelt, 'Civil society lobbying and countries' climate change policies: a matching approach', 13 Climate Policy, 2013, p. 702

40 ibid., p. 701-702.

41 ibid. 
sustainable development, and can dedicate a lot of resources on gathering and disseminating information relating to climate change related issues. ${ }^{\mathbf{4 2}}$ However, in this context it is noteworthy that NSAs are not necessarily a homogenic group and might represent different views amongst each other on issues that are difficult and prone to cause conflict. Nevertheless, the side events have proven to be very influential events as, for instance, when negotiations get stalled between parties in a COP, NSAs might manage to induce the negotiations again with their fervent action. ${ }^{\mathbf{4 3}}$

\subsection{Paris Agreement - Mitigation}

The Paris Agreement was a response to the fear that current efforts to hold global warming to below 2 or $1,5^{\circ} \mathrm{C}$ relative to pre-industrial levels was inadequate. The Agreement was adopted in the United Nation Climate Change Conference in Paris in $2015 .{ }^{44}$ The momentum that ultimately lead to the Agreement was, in fact, heavily influenced by NSAs. ${ }^{45}$ The negotiations consisted of nongovernmental organisations, trade unions, business, women and youth organisations, cities and regions, indigenous communities and different religious groups. ${ }^{46}$ These groups took on roles such as idea providers, implementers, knowledge brokers, watchdogs and lobbyists. Participating NSAs also represented marginal voices. ${ }^{\mathbf{4 7}}$

The Agreement's objectives are to limit global warming to less than $2^{\circ} \mathrm{C}$ above pre-industrial levels and to pursue efforts to limit the rise to $1,5^{\circ} \mathrm{C}$ and furthermore, enhance support for developing countries in order to carry that out. ${ }^{\mathbf{4 8}}$ In order to attain these goals, the Agreement establishes a system of mitigation ${ }^{\mathbf{4 9}}$ and adaption ${ }^{\mathbf{5 0}}$. Under mitigation the Agreement puts in place a system of NDCs, which relies on states making commitments to reduce emissions, adapt to climate change and provide finance. ${ }^{51}$ The system does not put in place legally binding targets but rather a process for transparent review designed to make states ratchet up these commitments over time. ${ }^{\mathbf{5 2}}$ The global stocktakes are meant to be periodical meetings in order to assess the collective progress towards achieving the goals of the Agreement. ${ }^{\mathbf{5 3}}$

42 ibid p. 702.; Yamin, 2001, p. 157.

43 Hermwille, 2018, p. 450

44 Lyster et al., 2016, p. 245

45 M. Danzo, 'Can non-state actors save the Paris Agreement?', 40 Michigan Journal of International Law, 2019, p. 1-2.; Van Tillburg et al., NDC Update Report: We have lifted off. New Climate Institute and Energy Research Centre of the Netherlands, 2017, p. 14.

46 J. Kuyper, 'Non-state actors in hybrid global climate governance: justice, legitimacy, and effectiveness in a post-Paris area'. WIREs Climate Change 9, 2018, p. 4.

47 ibid.

48 UNFCCC, Decision 1/CP.21: Paris Agreement, FCCC/CP/2015/L.9/Rev.1, Article 2

49 ibid., Article 4.

49 ibid., Article 4.

51 ibid., Article 7.

52 Bäckstrand \& Kuyper, 2017, p. 765.

53 Article 14 of the 2015 Paris Agreement.
The post Paris regime of the UNFCCC was a shift away from a top-down approach towards a bottom-up ${ }^{\mathbf{5 4}}$ approach and demonstrated the growing importance of NSAs in the international climate change regime. A meaningful outcome of the Agreement was making the UNFCCC as the central orchestrator of NSAs and transnational initiatives in the global climate governance. ${ }^{\mathbf{5 5}}$ The idea behind orchestration is that states and international organisations can mobilise or even catalyse the efforts of third parties in pursuit of some governance goal. ${ }^{\mathbf{5 6}} \mathrm{It}$ has been said that post Paris a 'hybrid multilateralism' landscape emerged in which both states and NSAs are central players in the climate change field. ${ }^{57}$

\subsection{Access and Participation}

Through NDCs, which are part of the mitigation strategy of the Agreement, NSAs can access and participate in the Agreement. Mitigation entails the maintaining of the increase of global average temperature to below $2^{\circ} \mathrm{C}$ and taking efforts to keep it below $1,5^{\circ} \mathrm{C} .{ }^{\mathbf{5 8}} \mathrm{NSA}$ participate by exerting their influence on participatory states in formulating their NDCs. Taking part in the formation process that ultimately leads to NDCs, NSAs can indirectly affect how the Paris Agreement plays out and whether its goals are achieved. NSAs can have this level of influence as the Agreement is a hybrid mix of bottom-up flexibility and top-down monitoring, reporting and review. ${ }^{\mathbf{5 9}}$ Bottom-up initiatives by NSAs are an integral part of the Agreement. In fact, the Paris Agreement recognises that NSAs are indispensable in the formation of NDCs due to their expertise and implementation capacity. ${ }^{60}$ NSAs function as watchdogs of the NDCs enhancing transparency, facilitating the stocktakes and pressuring for ratcheting up every five years. ${ }^{6}$ NSAs also have direct control over activities relevant to mitigation, such as transport structures in cities and electricity purchases by firms. ${ }^{62}$

\subsubsection{Influence}

NSAs might often be more ambitious than the state parties and, in that manner, can positively affect participating states' goals. ${ }^{\mathbf{6 3}}$ Currently the national ambitions of participating states

54 A bottom-up approach refers to action originating from the target groups as opposed to a top-down approach that refers to the relative authority of the actors who seek to produce an intended outcome. See: Kuyper et al., 2018, p. 6.

55 Bäckstrand \& Kuyper, 2017, p. 765.

56 Kuyper et al., 2018, p. 7 .

57 Danzo, 2019, p. 1-2.

58 Article 2 of the 2015 Paris Agreement: Lyster et al. 2016 p. 245-246.

59 Bäckstrand et al., 2017, p. 566

60 ibid., p. 568

61 ibid.; Kuyper et al., 2018, p. 2

62 Hale, 2018, p. 4

63 A. Hsu et al., 'Towards a new climate diplomacy', 5 Nature Climate Change, 2015, p. 501.; O. Widberg \& P. Pattberg, 'International Cooperative Initiatives in Global Climate Governance: Raising the Ambition Level or Delegitimizing the UNFCCC'. 6 Global Policy Volume 1, 2014, p. 45. 
are inadequate and are probably unable to alone achieve the agreed goal of limiting global warming to $2^{\circ} \mathrm{C} .{ }^{64} \mathrm{NSA}$ s have in fact been entrusted with the roles of reviewing the ambition of NDCs of different countries. ${ }^{65}$ The influence NSAs can exert over the formulation of NDCs can significantly affect the outcome of NDCs and through ratcheting up, the nation state's goals will become more ambitious every year. ${ }^{\mathbf{6 6}}$ In fact, NSAs help governments to overachieve in their pledges. ${ }^{67}$ Thus, NSAs are directly affecting the goals set out by the Paris Agreement through participating in formulating the NDCs. At a national level this can affect the implementation of legislative initiatives when states start to implement their goals - some NSAs are entrusted with the implementation of initiatives. ${ }^{\mathbf{6 8}}$ In fact, non-state actions are seen as both complements to and 'means of implementation' for national pledges. ${ }^{69}$

\section{RECOMMENDATIONS}

Non-state climate action has become a core feature of international climate governance. ${ }^{\mathbf{7 0}}$ This process, however, has been a slow one - it wasn't until the lead up to the Paris Agreement that the influence of NSAs towards climate change was recognised in a more official manner. Even though NSAs have had significant influence in climate change policy, initiatives and outcomes, there are still some points that can be raised concerning how the participation of NSAs in the Agreements can be improved. This chapter will provide three recommendations in this regard.

\section{I Role of Non-state Actors in Formulating Nationally Determined Contri- \\ butions}

An issue in the international climate change regime is the lack of teeth of NSAs - even though they are participating in climate change negotiations and in formulating national goals, they do not have de jure a formal role under the Agreements. The UNFCCC does not make any reference to either NSAs or observer organisations. ${ }^{\mathbf{7 1}}$ Within the framework of the Paris Agreement, the importance of NSAs has been recognised and stakeholders are encouraged to work closely with them, ${ }^{\mathbf{7 2}}$ however their role remains more as an influencer of states rather than an actor in

64 Widberg \& Pattberg, 2014, p. 53

65 Kuyper et al., 2018 , p. 9.

66 ibid., p. 5.

67 Hale, 2018, p. 4-5.

67 S. Chan et al., 'Reinvigorating International Climate Policy: A Comprehensive Framework for Effective

Non-state Action' 6 Global Policy 4, 2015, p. 469

69 ibid.

70 Van Asselt, 2016, p. 94-95

71 Kuyper et al., 2018, p. 4.

72 Danzo, 2019, p.1. their own right ${ }^{73}$. With the 2020 deadlines for the NDCs fast approaching it remains to be seen whether this new system created by the Paris Agreement, that requires state parties to make commitments that are not legally binding, will succeed or just act as a platform for action without creating actual solutions. ${ }^{\mathbf{7 4}}$ Concerns have been raised that national goals are not ambitious enough to put us on the track of achieving the temperature goal of below $2^{\circ} \mathrm{C} .^{75}$

Since NSAs are able to provide scientific and technical insight ${ }^{\mathbf{7 6}}$, are ambitious in climate change policy ${ }^{\mathbf{7 7}}$ and can impact the reduction of greenhouse gas emissions ${ }^{\mathbf{7 8}}$, it would be feasible to strengthen and, in a certain sense, formalise their role in the process leading to NDCs. This is even more so due to the discrepancy between states as to how much input they take from NSAs in formulating their NDCs. Even though international efforts have been made to catalyse nonstate action in formulating NDCs (mainly by holding a high level event every year and through the high level climate champions) ${ }^{\mathbf{7 9}}$, states should be further encouraged to include NSAs in the formulation and implementation of their NDCs. Such encouragement could take the form of a mandatory percentage of NSA participation. Each state party would be required to have a certain percentage of their NDCs implemented by NSAs or formulated in tandem with them. Then, in each five year cycle this percentage would gradually increase, augmenting NSA participation in the formation of NDCs. As the Paris Agreement has a bottom-up approach this would not disrupt its legal nature, but it would launch a comprehensive framework that aligns NSA and governmental actions over the long term.

\subsection{Participation of Non-state Actors in Conference of Parties}

As discussed in section 2.2, the influence NSAs exert on participating states during the COP negotiations is one of great significance. However, NSAs' participation to the negotiations can actually be hampered by the participatory states as they have the right to close the door from NSAs. ${ }^{\mathbf{8 0}}$ States might opt for a functional efficiency approach, in which they accept only NSAs that suit their interests to the negotiations. ${ }^{\mathbf{8 1}}$ As regards the side events, even though they have proven to be very effective ${ }^{\mathbf{8 2}}$ they are often physically held at a different location than the actual

73 Schroeder \& Lovell, 2012, p. 26.

74 By the time of publication of this study, participatory states should have submitted their amended or new NDCs. However, the Covid-19 pandemic might had an impact on this.

75 Van Tillburg et al., 2017, p. 16.

76 H. Van Asselt \& T. Hale, 'How non-state actors can contribute to more effective review processes under the Paris Agreement'. Stockholm Environment Institute, 2016, p. 1, 3.; Streck, 2012, p. 152.; Böhmelt, 2013 the Paris 701.
p.

77 Van Tillburg et al., 2017, p. 14

78 Danzo, 2019, p. 1.

78 Danzo, 2019, p. 1.

80 Kuyper et al., 2018, p. 3.

81 ibid.

82 Kuyper et al., 2018, p. 31.; Schroeder \& Lovell, 2012, p. 27. 
COP, thus perceived by many as something distinct from the actual negotiations. ${ }^{\mathbf{8 3}}$ Moreover, currently side events do not offer a framework to build a coordinated agenda between NSAs and the UNFCCC process. $^{\mathbf{8 4}}$

In order to prevent participatory states from closing the door to NSAs at COPs, mandatory NSA quotas could be set for party delegations. This would allow NSAs to always be represented at COPs. Regarding the side events, the agenda of attending NSAs should be better coordinated to the COP and its participants. Moreover, establishing a system of coherency between the different stakeholders at side events would be important for better organisation and categorisation of initiatives. This could be done by grouping all the topics and creating a report, which would later be made available to all COP participants. This would coordinate the information received from side events better and ensure that important initiatives are not missed and that they reach decision makers. Furthermore, the side events should be linked more formally to the actual COPs by holding them in the same location as the main event if possible, or in its proximity. This would result in less confusion about the nature of the side events. ${ }^{\mathbf{8 5}}$

\subsection{Improving the Non-state Actor Zone for Climate Action portal}

Concerns have been raised that current NDCs might not be enough to put us on the right track to limit global warming to below $2^{\circ} \mathrm{C}$. Meanwhile, it has been recognised that the activity of non-party stakeholders is essential to narrow the emission gap in limiting global temperature rise ${ }^{86} \mathrm{NAZCA}$ in particular is considered essential for states to ratchet up their commitments. ${ }^{\mathbf{8 7}}$ Currently the NAZCA portal contains more than 12,000 pledges by NSAs. ${ }^{\mathbf{8 8}}$ Therefore, NSA input does not seem to be the problem, but rather, how to merge these NSA initiatives to the NDCs on the one hand, and make sure that the pledges at the NAZCA portal actually advance and succeed. While NAZCA serves an important function in showcasing NSA initiatives, it could be improved to function also as a platform for NSAs to convene and furthermore, operate more strongly as a starting point from which implementation targets could be coordinated.

83 Schroeder \& Lovell, 2012, p. 27.

84 ibid., p. 34 .

85 Schroeder and Lovell suggest that side events could be organised around themes, such as forests and oceans. This would allow participants that can attend only for a shorter time, to benefit from attending events around their topic of interest. See: Schroeder \& Lovell 2012, p. 24-37.

86 Bäsckstrand \& Kuper, 2017, p. 770 .

87 ibid., p. 780.; UNFCCC, Decision 1/CP.21: Paris Agreement, FCCC/CP/2015/L.9/Rev.1, preamble 118. 88 ibid., p. 774 .
In the form NAZCA operates now, it serves moreover as a platform demonstrating ongoing NSA initiatives and has, in fact, been criticised ${ }^{\mathbf{8 9}}$ for lacking accountability and transparency. Considering the vast amounts of pledges made by different actors at the NAZCA portal, participating NSAs could learn and benefit from each other when it comes to planning and implementing climate action. Actors in the same categories, but also in different ones, could build up on each other's knowledge. In this regard, NSA participation could thus be improved by developing orchestration efforts further in order to catalyse cooperation amongst NSAs and in that manner, encourage the implementation of initiatives. NAZCA could move away from functioning as a displaying platform to a more operative platform, that would allow NSAs to convene. NAZCAs current role as an intermediary authority showcasing initiatives could be enhanced to include also the role of overlooking and monitoring initiatives bringing different actors together. Information sharing between NSAs would remain voluntary and at a low threshold..$^{90}$ This would enhance information sharing and efficiency leading to more effective outcomes as working across constituencies is especially important in climate change governance, since issues often affect multiple sectors. Furthermore, having increased coordinated initiatives across sectors might encourage states to implement their NDCs through these NSAs. Finally, if NAZCA were to bring different actors together to reach their individual goals, initiatives might be more inclined to succeed as there would be the fear of 'naming and shaming' from other NSAs if implementation is unsuccessful.

\section{CONCLUSION}

The international climate change regime is very different to what it was a few decades ago. The most prominent development has been the rise of the influence of NSAs in the field. A shift has occurred from a state centric to a hybrid multilateral landscape, where there is a mix and mingle of states and non-state actors. Within the framework of the UNFCCC and

89 See: Bäckstrand \& Kuyper 2017, p. 772-784. Karin Bäckstrand and Jonathan Kuyper have criticised NAZCA for lacking in accountability, transparency, participation and deliberation. Bäckstrand and Kuyper highlight issues concerning insufficient screening lack of criteria as to what constitute climate targets and weak monitoring mechanisms for assessment for affected stakeholders, such as individuals. Furthermore, they argue participation to be uneventy distributed and lacking important catego ortant categories of actors.

90 It should be noted that amending the intermediary role of NAZCA would still keep it separate to the LPAA. While the LPAA aims to catalyse robust action, the NAZCA portal would provide an avenue for NSAs to connect at a low threshold. This does not change the character of NAZCA as a voluntary bottom-up reporting system while LPAA is a high level orchestration effort. See: Kuyper et al., 2017, p. 774 
the Paris Agreement, NSAs can access and participate, and moreover influence law-making processes and outcomes, through orchestration, COPs and mitigation. Orchestration provides for a soft and indirect governance mode mobilising intermediaries to pursue collective goals. This has resulted in initiatives such as the NAZCA portal. Participation in COPs and their side events, allow NSAs to influence and take part in developing environmental law relating to climate change. Moreover, mitigation, the new system of NDCs developed under the Paris Agreement, is heavily based on NSA participation. NSAs both participate in formulating the NDCs together with states, and can also be responsible of implementing initiatives. However, regardless of these participation avenues, NSAs lack a formal role under the Agreements and therefore their influence is somewhat dependant on their reception by the participatory states to the Agreements. Moreover, as there are increasingly more NSAs that wish to participate in the climate change framework, innovative new ways of how to include and strengthen NSA participation should be come up with.

In relation to this, the system of NDCs and COPs could be developed slightly further. States should be further encouraged to include NSAs in the formulation and implementation of their NDCs. This could be done by imposing a mandatory percentage of NSA participation. In relation to COPs, NSA participation could be improved by imposing mandatory NSA quotas to party delegations, setting up a more coherent organisation and categorisation of initiatives and organising the side events better as they are often an important avenue for NSAs to voice their opinion. Moreover, the NAZCA portal could be developed further to function as a platform for NSAs to convene in order to catalyse more initiatives. These developments would be small steps to improve the dialogue between states and NSAs and could lead to better participation and more implementation of initiatives by NSAs. Moving forward we will surely continue to see more participation by NSAs in the international climate change regime. 